\title{
Sommergarten 2006
}

\section{Hans Gmür}

Korrespondenz: Dr. med. Hans Gmür Loretto CH-9108 Gonten
Der Garten war einst ein Ort der Ruhe und des Rückzugs vor Stress und Lärm, ein Ort beschaulichen Tuns in der Natur. Heute im Zeitalter der Motoren ist der Garten zu einem Tummelplatz von Maschinisten geworden. An schönen Tagen, kaum sind die Schneefräsen verstummt, lärmen und stinken im Quartier die Rasenmäher und viele anderen Motoren schön gestaffelt stundenlang durch die Gärten. Mit grossem Aufwand an Energie und Zeit werden die Gärten saubergemacht. Dabei wird die Luft verschmutzt mit Lärm und Abgasen und Hunderttausende von Tonnen Abfall werden produziert: sogenanntes Grüngut.

In einem modernen motorisierten Garten gelangen unter anderem folgende Motoren regelmässig zum Einsatz:

- Rasenmäher mit Benzinmotoren: Leistung 2,5-3,5 PS; Lärm: 80-100 Dezibel;

- Rasenmäher mit Elektromotoren: Leistung 1,6 kW; Lärm: unter 80 Dezibel;

- Rasentrimmer, Freischneider: Leistung: 0,82,0 kW; Lärm: bis 100 Dezibel;

- Vertikulierer: Leistung: 3,3 kW; Lärm: 85 Dezibel;

- Heckenscheren: Leistung: bis 0,6 kW; Lärm: 85-95 Dezibel;

- Motorsägen: Leistung: 1,5 kW, 2,0 PS; Lärm: um 110 Dezibel;

- Gartenhäcksler, Schredder: Leistung: 1,6 kW; Lärm: bis 75 Dezibel;

- Laubbläser (selten in Privatgärten): Leistung: 2,8 kW; Lärm: bis 112 Dezibel.

Lärm ist für viele Menschen das Umweltproblem «Nummer eins». Rund 80\% unserer Zeitgenossen fühlen sich durch Strassenverkehr, knapp $50 \%$ durch Fluglärm, um die 30\% durch Nachbarschaftslärm und etwa 20\% durch Industrieund Gewerbelärm belästigt. Über 40\% der Bevölkerung halten Lärm für gesundheitsschädigend.

Tatsächlich ist es erwiesen, dass Lärm nervt und krank macht. Eine Beschallung über 85 Dezibel führt zu Gehörschäden. Die Schmerzgrenze liegt bei 110 Dezibel. Eine chronische Lärmbelastung führt im Organismus zu Stressreaktionen: Der Körper schüttet die Stresshormone Adrenalin und Noradrenalin aus. Es treten Schlafstörungen auf, Bluthochdruck, Herzkrankheiten.
Der Vater trägt drum manchmal einen Gehörschutz, wenn er mit dem Rasenmäher oder mit dem Freischneider im Garten wirkt. Dies ist sehr zu loben. Daneben spielen die Kinder, jätet die Gattin: ohne Gehörschoner!

Alle Verbrennungsmotoren stossen Abgase aus und führen zur Luftverschmutzung mit Kohlendioxid, Kohlenmonoxid, Stickoxiden, Feinstaub, Kohlenwasserstoffen, flüchtigen organischen Verbindungen wie Benzol. Diese Schadstoffe führen zu Erkrankungen der Atemwege, besonders bei Kindern und älteren Leuten.

Ein Rasenmäher, betrieben mit einem BenzinÖl-Gemisch, stösst Abgase aus, die ebensoviel krebserzeugende Kohlenwasserstoffe enthalten wie 200(!) Autos mit geregeltem Katalysator (nach Umwelt- und Gesundheitsschutz der Stadt Zürich).

Der Garten ist ein stressiger, ungesunder Ort geworden. Nur an Sonntagen und Regentagen kehrt Ruhe ein.

Wie kann das verbessert werden?

- Wenn für Ihr Gartenglück ein Rasenstück unentbehrlich ist, dann lassen Sie doch einen Magerrasen wachsen. Dieser braucht weder Dünger, noch Herbizide und muss seltener gemäht werden.

- Benützen Sie wenn möglich mechanische Rasenmäher ohne Motor: Tun Sie etwas für Ihre Fitness!

- Für Rasenmäher mit Benzinmotoren sollten strengere Lärm- und Abgasvorschriften erlassen und die Verwendung von Ökobenzin für obligatorisch erklärt werden.

Wenn Sie Ihr Grundstück weder für Spiel und Sport noch für Gemüseanbau benützen, sondern nur alle fünf bis sieben Tage einmal begehen zum Rasenmähen, dann empfehle ich Ihnen: Lassen Sie einfach eine Wiese wachsen und beobachten Sie, welche Gräser, Blumen, Kräuter und auch Heilkräuter spriessen und erblühen. Es ist ein Wunder, Sie werden staunen, was sich auf einem einigermassen gesunden Boden spontan entfaltet. Ich weiss, es gibt Menschen, die Blumen nicht gerne haben und sie entweder vergiften, mit dem Rasentrimmer auch im entferntesten 
Winkel des Gartens aufspüren und verschnetzeln oder - etwas umweltfreundlicher - ausstechen. Da ist wohl guter Rat teuer. Wenn Sie aber Pflanzen und Blumen lieben, dann können Sie sich jeden Tag freuen an den unentgeltlichen Geschenken der Natur.

Geben Sie der Artenvielfalt wenigstens in Ihrem Garten eine Chance.

Viele Bauern sind aus wirtschaftlichen Gründen gezwungen, ihren Grund und Boden intensiv zu nutzen zum Anbau von Futter, Lebensmitteln und zunehmend auch zur Produktion von Bioenergieträgern. Die Landwirte bevorzugen auf ihren Wiesen und Feldern das saubere Einheitsgrün von Monokulturen und haben wenig Verständnis für Artenvielfalt und Ökoplätz. So war es jedenfalls zu lesen in einem Artikel im «Appezöller Buur» vom 12. April 2006. Eveline Dudda berichtete darin über die Dissertation von Luzia Jurt, welche die Einstellung der Bauern zu Ökoausgleichsflächen und Biodiversität analysierte.

Wir Konsumenten sind auch schuld an dieser Entwicklung in der Landwirtschaft: Wir wollen möglichst billige Lebensmittel.

Die Pflege der Artenvielfalt hat indessen nicht nur Bedeutung für das Überleben einiger Käfer, Schmetterlinge, Feldlerchen und Pflanzen, sondern ist entscheidend auch für das Überleben der Menschheit.
Eine Blumenwiese müssen Sie zweimal mähen im Jahr. Dafür ist der Rasenmäher ungeeignet.

Lernen Sie mähen mit der Sense! Muskeln statt Motoren! Das erhält Sie fit und geschmeidig, und Sie hören bei der Arbeit in Ihrem Garten die Vögel pfeifen. Kurse für das Mähen mit der Sense werden von verschiedenen Institutionen angeboten. Das Heu können Sie oder der Nachbar den Kaninchen verfüttern. Oder ein Bauer nimmt ihnen sicher gerne einen Schlumpf Heu ab.

Stutzen Sie eine Hecke mit der Handschere zurecht. Büsche und Sträucher, ja sogar kleinere Bäume lassen sich gut mit der Handsäge fällen und zersägen. Besen und Rechen ersetzen effektiv und lärmfrei den Laubbläser. Ein Scheitstock und ein Gertel ersetzen den Schredder, der ohnehin immer wieder verstopft ist.

Muskeln statt Motoren!

Wenn Sie altershalber oder aus gesundheitlichen Gründen nicht imstande sind, Ihre Wiese selber zu mähen, dann helfen Ihnen sicher Verwandte, Nachbarn, junge Menschen aus, die gerne ihr Sackgeld mit einer solchen Dienstleistung aufbessern: Jugendforum, Jungwacht, Pfadfinder, Beschäftigungsprogramm für Arbeitslose usw.

So wünsche ich Ihnen einen lärm- und abgasfreien Sommer. Geniessen Sie die erholsame Ruhe in Ihrem Garten. Freuen Sie sich am Gesang der Vögel, an der vielfältigen Pflanzenwelt und an den bunten Blumen. 